\title{
Are there any correlations between social and hand functions in patients with carpal tunnel release surgery postoperatively?
}

\author{
Alfonse Marchie BSc MSc ${ }^{1}$, James Mahoney MD FRCSC ${ }^{1,2}$
}

\begin{abstract}
A Marchie, J Mahoney. Are there any correlations between social and hand functions in patients with carpal tunnel release surgery postoperatively? Can J Plast Surg 2008;16(4):216-220.

BACKGROUND: Carpal tunnel syndrome is one of the most common and disabling work injuries in North America. Patients with carpal tunnel syndrome are often associated with substantial productivity loss and cost both at work and at home. Several studies have examined the relationship of social supports as a predictor of returning to work following carpal tunnel release surgery (CTRS). However, no studies published to date have examined the relationship between social support and the ability to perform activities of daily living after having CTRS.

OBJECTIVE: To examine whether a correlation exists between the degree of social support and hand function in terms of the ability to perform activities of daily living in patients who have had CTRS.

METHODS: Patients in the present cross-sectional study were evaluated with two standardized questionnaires at least two months postoperatively following CTRS. The questionnaires consisted of the Multidimensional Scale of Perceived Social Support, which evaluated social support, and QuickDASH, which evaluated hand function. A correlation analysis was then performed to identify any relationships between the two questionnaires.

RESULTS: In a sample of 20 patients, correlation analyses revealed that perceived social support was significantly associated with hand function scores postoperatively $(r=-0.73, \mathrm{P}<0.01)$. In addition, a statistically significant relationship existed between social support and the preoperative selfrating pain scores $(r=-0.51, \mathrm{P}<0.05)$. These results indicate that there is a strong association between the degree of social support and the ability to perform hand activities of daily living following CTRS.
\end{abstract}

Keywords: Activities of daily living; Carpal tunnel release surgery; Carpal tunnel syndrome; Hand function; Social support

\author{
Y a-t-il des corrélations entre le fonctionnement \\ social et la fonction manuelle chez les patients \\ après une chirurgie pour syndrome du tunnel \\ carpien?
}

HISTORIQUE : Le syndrome du tunnel carpien est l'un des accidents du travail les plus répandus et les plus invalidants en Amérique du Nord. Chez les patients qui en souffrent, le syndrome du tunnel carpien occasionne souvent une perte de productivité et des coûts substantiels, tant au travail qu’à la maison. Plusieurs études se sont penchées sur le rôle du réseau social en tant que facteur prédicteur du retour au travail après une chirurgie pour syndrome du tunnel carpien (STC). Toutefois, aucune étude publiée à ce jour n'a analysé le lien entre le réseau social et la capacité de s'acquitter des tâches de la vie courante après une chirurgie pour STC.

OBJECTIF : Vérifier s'il existe une corrélation entre le degré de soutien social et la fonction manuelle pour ce qui est de la capacité de s'acquitter des tâches de la vie courante chez les patients qui ont subi une chirurgie pour STC.

MÉTHODES : Les patients de la présente étude transversale ont été évalués au moyen de deux questionnaires standardisés au moins deux mois après leur intervention pour STC. Les questionnaires étaient les échelles Multidimensional Scale of Perceived Social Support pour le réseau social, et QuickDASH, pour la fonction manuelle. Une analyse de corrélation a ensuite été effectuée afin de relever tout lien entre les deux questionnaires. RÉSULTATS : Sur un échantillon de 20 patients, les analyses de corrélation ont révélé que la solidité perçue du réseau social était significativement associée aux scores de fonction manuelle en période post-opératoire $(\mathrm{r}=-0,73, \mathrm{p}<0,01)$. En outre, un lien statistiquement significatif a été noté entre le réseau social et les scores d'auto-évaluation de la douleur préopératoire $(r=-0,51, p<0,05)$. Ces résultats confirment qu'il existe un lien étroit entre la solidité du réseau social et la capacité de s'acquitter des activités manuelles de la vie courante après une chirurgie pour STC.
F rom prehistory to modern society, the ability to use one's hands has been critical for human survival. Defense, acquisition and preparation of food, work-related activities, communication and expression of affection are just a few of the activities that depend on having full use of one's hands.

Because humans use their hands so often for all kinds of activities, it is not surprising that they also may be affected by many disorders, including traumatic repetitive injuries. One of the more common and disabling hand disorders is carpal tunnel syndrome (CTS) (1). CTS is caused by the compression of the motor and sensory nerve in the wrist (median nerve), resulting in pain, muscle weakness, numbness and tingling in the hand. The reported prevalence of CTS in the general population ranges from $0.7 \%$ to $9.2 \%$ among women and from $0.4 \%$ to $2.1 \%$ among men (2).

Because work-related upper extremity disorders such as CTS are associated with substantial work productivity loss and cost (3), most studies to date have examined the relationship between CTS and its effects on the working environment. For example, in one community-based study (4), individuals with worse baseline CTS symptom severity, functional status and mental health were less likely to be working six months after carpal tunnel release surgery (CTRS).

Few studies have examined social support as a predictor of work outcomes among individuals who undergo CTRS. For instance, in one study, individuals with greater psychological distress, low job social support, and high psychological job demands were less likely to have successfully returned to work six months after CTRS (5).

Although work outcomes related to social support is definitely of great value, we believed that it was equally important to learn about the relationship between social support and the ability to perform activities relating to daily living in carpal tunnel surgery postoperatively. This is because health profes- 
sionals frequently refer to the ability to perform activities of daily living (ADL) as a measurement of the functional status of the individual. These measurements are useful for assessing postoperative patients, the elderly and the mentally ill in order to evaluate what type of health care services they may need.

Surprisingly, there are no published data on the relationship between social supports and hand function (in the ability to perform ADL) in patients who have had CTRS. The present study investigated whether there are any correlations between the degree of social support and the ability to perform ADL in patients who have had CTRS.

\section{METHODS}

In February and March 2008, 37 patients who had been treated by the same surgeon in the Department of Plastic Surgery at St Michael's Hospital (Toronto, Ontario) for carpal tunnel release from January 1 to December 31, 2007, were mailed information regarding the objectives of the present crosssectional study. They were asked to fill out two questionnaires and return them in an enclosed, self-addressed, stamped envelope. Those who did not return the completed questionnaires within one week of letters being sent were contacted by telephone to inquire about their interest in participating in the study. No identifying information was obtained. Only patients 18 years of age or older were eligible for the study, and participation in the study was entirely voluntary with full informed consent. Ethics approval was granted by the Research Ethics Board at St Michael's Hospital.

\section{Questionnaires}

The degree of social support as perceived by the patient was measured using the Multidimensional Scale of Perceived Social Support (MSPSS) (Appendix) (6). The MSPSS is a 12-item instrument employing a seven-point scale $(1=$ very strongly disagree; $7=$ very strongly agree). The total MSPSS score plus three factors - analytically derived subscale scores addressing perceived support from family, friends and significant others were obtained. Representative items included: "I get the help and support I need from my family", and "My family really tries to help me". The test-retest reliability for the total and three subscales was $0.85,0.72,0.85$ and 0.75 , respectively. The MSPSS has been shown to have good internal reliability (7).

Three additional questions were included as part of the present study. They were:

1. On a scale of 0 to 10 ( 0 being no pain and 10 being the worst pain you have felt in your life), how would you rate the amount of pain you felt before surgical treatment of the hand was initiated?

2. Do your finances worry you? $(1=$ never, $2=$ rarely, $3=$ sometimes, $4=$ most of the time, $5=$ always $)$.

3. Are you presently on any pain medication (Yes or No)?

The ability to perform daily activities as a measure of hand function/symptom was recorded by the QuickDASH questionnaire. The QuickDASH questionnaire consists of an 11-item disability/symptom scale intended as a self-report outcome measure for people with upper extremity disorders. It has been shown to have reliability, cross-sectional validity and longitudinal validity in a variety of arm disorders (8). The items ask about the degree of difficulty in performing different physical activities because of hand problems, the severity of each of the symptoms of pain, tingling and weakness, as well as the problem's impact on social activities, work and sleep. Each item in the disability/symptom scale has five response options ranging from "no difficulty" to "unable". Sample questions include: "Please rate your ability to open a tight or new jar", and "Please rate your ability to wash your back".

\section{Statistics}

Analyses were performed using SPSS version 15.0 (SPSS Inc, USA) statistical software. To determine the association between social support (MSPSS) and hand function outcomes (QuickDASH), a correlation analysis was performed and a Pearson correlation coefficient was calculated. Additional correlation analyses were performed among the variables 'financial concerns', 'sex', 'age', 'use of pain medications', 'date of operation' and 'pain self-rating preoperation', along with the three individual components of the social support questionnaire (family, friends and significant others). The strengths of the MSPSS and QuickDASH questionnaires rest on the fact that they are both concise and simple to understand. This ensures some degree of consistency in terms of having the questionnaire properly completed, and it increases the likelihood of participation by potential subjects. However, because only the English versions of the MSPSS and QuickDASH were sent to potential subjects, those who were less fluent in English would be less likely to complete the questionnaire.

For the analyses of age, patients were divided into either 65 years of age and older, or younger than 65 years of age. Sixtyfive years is typically associated with the age of retirement, and patients were divided to see if there were differences between those who were retired versus those who were not in relation to issues such as social support and postoperative hand function. Furthermore, it was decided to divide patients into two groups by date of operation (before or after June 30, 2007), to avoid having a number of patients cluster for certain months of the year.

\section{Demographic results}

\section{RESULTS}

From a potential group of 37 patients, 22 completed the study. Two subjects had their results voided due to having improperly filled out the QuickDASH questionnaires (as defined by the scoring standards of the questionnaire), resulting in a total of 20 subjects ( 14 women, six men; mean [ $\pm \mathrm{SD}$ ] age $59.8 \pm 15.2$ years, range 29 to 86 years).

\section{Data results}

Table 1 shows the mean \pm SD scores for the various measures, and Table 2 reports on the Pearson correlation among the various measures. The results of the correlation analyses revealed that perceived social support (MSPSS) was significantly associated with QuickDASH scores after at least two months postoperatively $(\mathrm{r}=-0.73, \mathrm{P}<0.01)$; therefore, higher levels of social support were significantly associated with lower disability/symptoms scores (Figure 1). Furthermore, it is interesting to note that among the MSPSS questionnaires, support from significant others $(r=-0.71)$ had the greatest correlation with hand function/symptoms scores. Although support from family $(r=-0.58)$ was also significantly related to hand function scores, support from friends $(\mathrm{r}=-0.56)$ was only associated with hand function at the $\mathrm{P}<0.05$ level. In addition, a statistically 
TABLE 1

Total scores for various measures $(n=20)$

\begin{tabular}{lccc}
\hline & Minimum & Maximum & Mean \pm SD \\
\hline Age & 29.0 & 86.0 & $59.75 \pm 15.23$ \\
DASH & 2.27 & 88.64 & $32.36 \pm 23.43$ \\
MSPSS & 18.0 & 84.0 & $60.85 \pm 20.09$ \\
MSPSS (FAM) & 4.0 & 28.0 & $20.25 \pm 8.55$ \\
MSPSS (SO) & 5.0 & 28.0 & $21.2 \pm 7.17$ \\
MSPSS (FR) & 4.0 & 28.0 & $19.4 \pm 8.17$ \\
VAS & 3.0 & 10.0 & $7.45 \pm 1.99$ \\
Finance & 1.0 & 5.0 & $3.00 \pm 1.03$ \\
\hline
\end{tabular}

DASH QuickDASH scores; MSPSS Multidimensional Scale of Perceived Social Support; MSPSS (FAM) Family component of the MSPSS questionnaire; MSPSS (FR) Friends component of the MSPSS questionnaire; MSPSS (SO) Significant other component of the MSPSS questionnaire; VAS Visual analogue scale (preoperative self-rating pain score)

significant relationship existed between social support and the preoperative self-rating pain scores $(\mathrm{r}=-0.51 ; \mathrm{P}<0.05)$ (ie, patients with greater social interactions had a lower self-rating pain scores preoperatively).

There was a significant correlation between the use of pain medication and male sex $(\mathrm{r}=-0.58 ; \mathrm{P}<0.05)$.

No significant relationship was observed between the date of hand operation and either hand function scores $(r=0.3)$ or social support $(\mathrm{r}=-0.15)$. In addition, no correlations were found among variables of age, use of pain medications, financial concerns, hand function scores and social support levels. However, there was some relationship between age and one's financial concern $(r=0.52 ; \mathrm{P}<0.05)$. Older patients tended to have less concern about their financial well-being compared with younger patients.

\section{DISCUSSION}

The present study attempted to provide a cross-sectional view of the effects of social support on surgical recovery in patients who underwent CTRS. By independently assessing the variables of social support (MSPSS) and hand function (QuickDASH) via two questionnaires, we discovered that post-treatment levels of social support reported by patients who underwent CTRS were significantly correlated with their hand function/symptoms outcomes. That is, patients who had a greater degree of social support through family, friends or

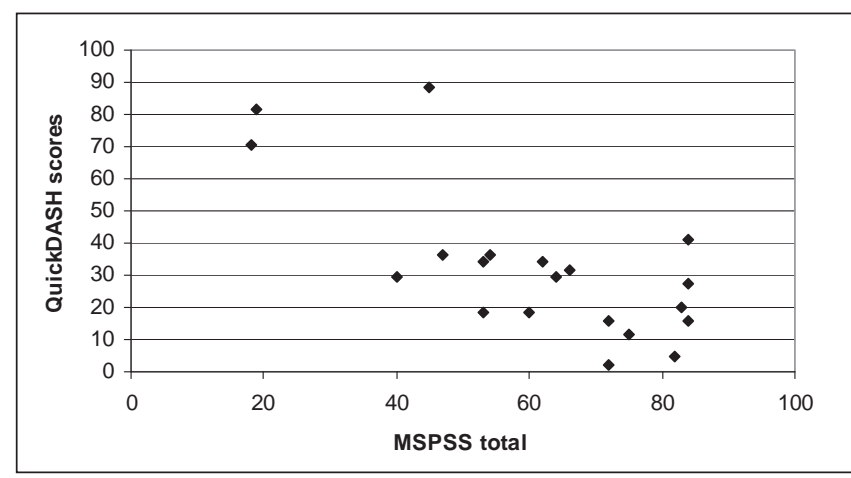

Figure 1) Correlation between QuickDASH and perceived social support. MSPSS Multidimensional Scale of Perceived Social Support

significant others tended to have less symptoms and a greater degree of hand function in their ADL postoperatively. These results are not very surprising given the fact that numerous studies have reported the beneficial effects of social support on personal health. For instance, there is evidence linking both emotional and instrumental support to less extensive development of coronary atherosclerosis (7). Other studies (9) have demonstrated a better survival postmyocardial infarction for those with more emotional support.

Although the relationship between social support and postoperative physical health outcomes have been less well documented, recent studies have shown that social support has a positive influence on recovery from hospitalization and medical procedures. For instance, one study (10) showed that patients with a large support network of family and friends report feeling less pain and anxiety before a surgical procedure, which can have a substantially positive impact on their postoperative recovery. The findings from this study support our results; we also found that patients with greater social interactions had a lower pain rating preoperatively. It can be hypothesized that a greater degree of social support has a positive effect on the mental health of the individual, which, in turn, may give the person a greater degree of resiliency to tackle problems associated with their physical health. That is, patients may believe that they can depend on someone who will be willing to help them should they encounter obstacles associated with their health.

TABLE 2

Pearson correlations among clinical variables $(n=20)$

\begin{tabular}{|c|c|c|c|c|c|c|c|c|c|c|c|}
\hline & DASH & MSPSS & Sex & Age & DOO & Meds & VAS & Finance & $\begin{array}{c}\text { MSPSS } \\
\text { (FAM) }\end{array}$ & $\begin{array}{c}\text { MSPSS } \\
\text { (SO) }\end{array}$ & $\begin{array}{c}\text { MSPSS } \\
\text { (FR) }\end{array}$ \\
\hline$\overline{\text { DASH }}$ & 1.0 & & & & & & & & & & \\
\hline MSPSS & $-0.726^{\star \star}$ & 1.0 & & & & & & & & & \\
\hline Sex & 0.299 & -0.179 & 1.0 & & & & & & & & \\
\hline Age & 0.322 & -0.356 & -0.066 & 1.0 & & & & & & & \\
\hline doo & 0.255 & -0.116 & $0.535^{\star}$ & 0.287 & 1.0 & & & & & & \\
\hline Meds & -0.285 & 0.03 & $-0.579^{\star *}$ & 0.082 & -0.25 & 1.0 & & & & & \\
\hline VAS & 0.431 & $-0.485^{\star}$ & 0.13 & 0.262 & -0.074 & -0.021 & 1.0 & & & & \\
\hline Finance & 0.219 & -0.278 & 0.109 & $0.503^{*}$ & 0.204 & 0.0 & 0.207 & 1.0 & & & \\
\hline $\begin{array}{l}\text { MSPSS } \\
\text { (FAM) }\end{array}$ & $-0.583^{\star *}$ & $0.801^{\star \star}$ & -0.308 & -0.419 & -0.282 & 0.147 & -0.147 & -0.276 & 1.0 & & \\
\hline MSPSS (SO) & $-0.706^{\star \star}$ & $0.882^{\star \star}$ & 0.028 & -0.219 & 0.053 & -0.05 & $-0.465^{\star}$ & -0.143 & $0.553^{*}$ & 1.0 & \\
\hline MSPSS (FR) & $-0.556^{\star}$ & $0.847^{\star *}$ & -0.143 & -0.245 & -0.036 & -0.036 & $-0.632^{\star *}$ & -0.27 & 0.437 & $0.714^{\star *}$ & 1.0 \\
\hline
\end{tabular}

${ }^{*}$ Correlation is significant at the 0.05 level (2-tailed); ${ }^{* *}$ Correlation is significant at the 0.01 level (2-tailed). DASH QuickDASH scores; DOO Date of operation; Meds Medications; MSPSS Multidimensional Scale of Perceived Social Support; MSPSS (FAM) Family component of the MSPSS questionnaire; MSPSS (FR) Friends component of the MSPSS questionnaire; MSPSS (SO) Significant other component of the MSPSS questionnaire; VAS Visual analogue scale (preoperative self-rating pain score) 
Moreover, sharing time with family, friends and significant others may in fact help distract a patient from thinking about his or her own physical pain and symptoms and, hence, report better health outcomes.

Another interesting finding from the present study was that having significant others for social support had the greatest correlation with the hand function/symptoms scores; friends and family were also associated with having better hand function. These results differ slightly from a study conducted by Uchino et al (11). In their study, they found that social contact with family members, but not friends, was the best predictor of lowering blood pressure. However, it may be difficult to compare our study with that of Uchino et al, because the health condition being studied was quite different. For instance, elevated blood pressure is typically asymptomatic and can be lowered by lifestyle modification, whereas carpal tunnel release is typically symptomatic for several weeks after the surgery.

In one study from the United States (12), social support was found to vary positively with socioeconomic status. Research also suggests that social stressors that are more prevalent in lower socioeconomic status environments (eg, residential crowding, fear of crime, financial strain) are associated with lower perceived support, contributing to reductions in reported levels of social support because they tend to foster a distrust of others (13). However, in our study, there was a lack of financial correlation with either social support or hand function. It is important to clarify that our assessment of financial status was based solely on one question ("Do your finances worry you?"). This may not necessarily be the most accurate representation of one's financial condition.

\section{STRENGTH AND LIMITATIONS}

A major strength of the present study was the fact that the same surgeon operated on each participant. This is in contrast to similar studies that have had multiple surgeons operating on the patient pool. Hence, in our study, variations in postoperative hand recovery was not a function of variations in surgical skill. Another strength of the present project was its simplicity, in that it only entailed mailing two questionnaires and tabulating the results.

However, a limitation of the study is that the conclusions were derived from two questionnaires, and it is difficult to conclusively state that there is a cause and effect relationship between social support and postoperative hand function. Because we did not look at the medical charts of the study patients, we do not know other potentially important information such as whether the operation was on the dominant or nondominant hand; medical and surgical history, and how it may have affected the healing process; and patient occupation. However, although it is possible that these elements may have had an influence on hand function, they would not have had any influence on social support, and access to charts may not have been relevant. Some may argue that patients who have had previous operations may be better able to tolerate the pain and discomfort associated with carpal tunnel release and, hence, they would have a lower disability/symptom score. By the same token, it could be argued that a higher pain threshold would necessitate a decrease in use of pain medications postoperatively. In our study, the use of pain medication postoperatively had no correlation with hand function scores.
A second limitation of the present study is the small sample size $(n=20)$. While it may be difficult to obtain meaningful results from such a small sample, our response rate was $60 \%$, which is higher than the average response rates for mailed questionnaires (14). A third limitation of the present study is the lack of established 'gold standard' measures for both social support and hand function. The variety of different measures currently in use makes it difficult to draw conclusions based on comparisons of results across studies.

A fourth limitation of the present study relates to the variability with which the survey questionnaires were sent in relation to the date of surgery for each patient. Because of the cross-sectional retrospective design of the study, some patients received their questionnaires two months postoperatively, while others may have been contacted six months postoperatively. However, in our study, we did not find any relationship among QuickDASH, MSPSS and timing of the operation. Furthermore, in general, surgical procedures require an average healing time of six weeks. In our study, every subject who was contacted had a healing time of at least two months.

\section{CONCLUSIONS}

Although this study may be interpreted as subjective, it does carry some important value as the surveys indicate to us what the patient was telling us about themselves. We have interpreted the results as follows for patient who have had CTRS: "If I know I have someone who cares about me, then I am less likely to feel pain and disability months after the surgery." For subjects who gave both poor social rating and hand function scores it may be interpreted as a subconscious cry for help because they may feel as though no one cares about their well being.

In short, these findings suggest that it is important for clinicians to be aware of the relationship between patients' social networks and their impact on their recovery after major operations. Clinicians can simply bring this awareness to their patients by informing them of the importance of social interactions and health outcomes and how they should try to ensure that there is social support after any physical intervention such as surgery.

In the future, a follow-up study may be conducted to include a larger sample size. However, a larger sample size may necessitate that patients from more than one hospital and hence, more than one surgeon be included. Secondly, a prospective study may be designed such that the hand functions of patients are followed consistently over time such as one month preoperatively, then a six-month and one-year period postoperatively. Finally, one would ensure that one has access to the medical history of the patient, so that factors, such as previous hand surgeries, occupation, left or right hand dominance, can be accounted for in the analysis.

ACKNOWLEDGEMENTS: Special thanks to Dr Mahoney for his guidance, supervision and willingness to help with this project, as well as Helen, Mrs Mahoney and the staff at the Martin Family Centre for Arthritis Care and Research, St Michael's Hospital, Toronto, Ontario, for making this project go through smoothly. 


\section{APPENDIX}

Multidimensional Scale of Perceived Social Support (6)

\begin{tabular}{|c|c|c|c|c|c|c|c|c|c|}
\hline \multicolumn{5}{|c|}{ 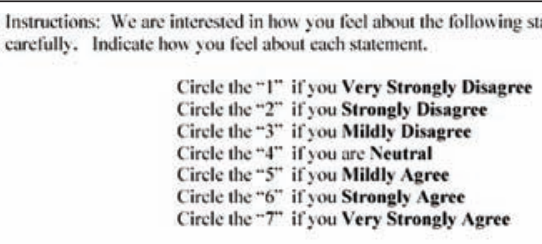 } & & & & & \\
\hline 1. & $\begin{array}{l}\text { There is a special person who is around when } 1 \\
\text { am in need. }\end{array}$ & 1 & 2 & 3 & 4 & 5 & 6 & 7 & so \\
\hline 2. & $\begin{array}{l}\text { There is a special person with whom I can share } \\
\text { my joys and sorrows. }\end{array}$ & 1 & 2 & 3 & 4 & 5 & 6 & 7 & so \\
\hline 3. & My family really tries to help me. & 1 & 2 & 3 & 4 & 5 & 6 & 7 & Fam \\
\hline 4. & $\begin{array}{l}\text { I get the emotional help and support I need from } \\
\text { my family. }\end{array}$ & 1 & 2 & 3 & 4 & 5 & 6 & 7 & Fam \\
\hline 5. & $\begin{array}{l}\text { I have a special person who is a real souree of } \\
\text { comfort to me. }\end{array}$ & I & 2 & 3 & 4 & 5 & 6 & 7 & so \\
\hline 6. & My friends really try to help me. & 1 & 2 & 3 & 4 & 5 & 6 & 7 & Fri \\
\hline 7. & I can count on my friends when things go wrong. & 1 & 2 & 3 & 4 & 5 & 6 & 7 & Fri \\
\hline 8. & I can talk about my problems with my family. & 1 & 2 & 3 & 4 & 5 & 6 & 7 & Fam \\
\hline 9. & $\begin{array}{l}\text { I have friends with whom I can share my joys } \\
\text { and sorrows. }\end{array}$ & 1 & 2 & 3 & 4 & 5 & 6 & 7 & Fri \\
\hline 10. & $\begin{array}{l}\text { There is a special person in my life who cares } \\
\text { about my feelings. }\end{array}$ & 1 & 2 & 3 & 4 & 5 & 6 & 7 & so \\
\hline 11. & My family is willing to help me make decisions. & 1 & 2 & 3 & 4 & 5 & 6 & 7 & Fam \\
\hline 12. & I can talk about my problems with my friends. & 1 & 2 & 3 & 4 & 5 & 6 & 7 & Fri \\
\hline
\end{tabular}

\section{REFERENCES}

1. Daniell WE, Fulton-Kehoe D, Chiou LA, Franklin GM. Workrelated carpal tunnel syndrome in Washington State workers' compensation: Temporal trends, clinical practices, and disability. Am J Ind Med 2005;48:259-69.

2. Andersen JH, Thomsen JF, Overgaard E, et al. Computer use and carpal tunnel syndrome: A 1-year follow-up study. JAMA 2003;289:2963-9.

3. Cheadle A, Franklin G, Wolfhagen C, et al. Factors influencing the duration of work-related disability: A population-based study of Washington State workers' compensation. Am J Public Health 1994;84:190-6.

4. Katz JN, Keller RB, Fossel AH, et al. Predictors of return to work following carpal tunnel release. Am J Ind Med 1997;31:85-91.

5. Gimeno D, Amick BC III, Habeck RV, Ossmann J, Katz JN. The role of job strain on return to work after carpal tunnel surgery. Occup Environ Med 2005;62:778-85.

6. Zimet GD, Dahlem NW, Zimet SG, Farley GK. The Multidimensional Scale of Perceived Social Support. J Pers Assess 1988;52:30-41.

7. Blumenthal JA, Burg MM, Barefoot J, Williams RB, Haney T, Zimet G. Social support, type A behavior, and coronary artery disease. Psychosom Med 1987;49:331-40.

8. Hudak PL, Amadio PC, Bombardier C. Development of an upper extremity outcome measure: the DASH (disabilities of the arm, shoulder and hand) [corrected]. The Upper Extremity Collaborative Group (UECG). Am J Ind Med 1996;29:602-8.

9. Lett HS, Blumenthal JA, Babyak MA, et al. Social support and prognosis in patients at increased psychosocial risk recovering from myocardial infarction. Health Psychology 2007;26:418-27.

10. Mitchinson AR, Kim HM, Geisser M, Rosenberg JM, Hinshaw DB. Social connectedness and patient recovery after major operations. J Am Coll Surg 2008;206:292-300.

11. Uchino BN, Cacioppo JT, Kiecolt-Glaser JK. The relationship between social support and physiological processes: a review with emphasis on underlying mechanisms and implications for health. Psychol Bull 1996;119:488-531.

12. Tausig M, Fenwick R. Recession and well-being. J Health Soc Behav 1999;40:1-16.

13. Lepore SJ, Evans GW, Schneider ML. Dynamic role of social support in the link between chronic stress and psychological distress. J Pers Soc Psychol 1991;61:899-909.

14. Eaker S, Bergström R, Bergström A, Adami HO, Nyren O. Response rate to mailed epidemiologic questionnaires: a population-based randomized trial of variations in design and mailing routines. Am J Epidemiol 1998;147:74-82. 